\title{
Saberes docentes: um olhar sobre as práticas pedagógicas no ensino de pós-graduação
}

\begin{abstract}
RESUMO: O presente artigo apresenta os resultados de uma pesquisa realizada no contexto de um curso de Mestrado de uma Universidade pública da Bahia, Brasil, cujo objetivo foi analisar a prática pedagógica ali desenvolvida, a partir da percepção dos próprios professores. Após análise da atual conjuntura social e político-econômica brasileira que fizeram emergir os mestrados de natureza profissionalizante, procurou-se identificar os saberes dos docentes acerca da natureza e especificidades do currículo do próprio curso e a articulação deste com os objetivos, os métodos de ensino, o planejamento integrado e condutas de avaliação utilizadas. Essa pesquisa emergiu de uma prática de formação continuada instituída no espaço dos ateliers didáticos (espécie de oficinas didáticas); estes espaços serviram para registro dos dilemas profissionais, dúvidas, questionamentos e saberes docentes. Esses registros, realizados ao longo de um ano, serviram de base para o conhecimento pessoal e prática profissional dos docentes. No recorte que fizemos, os saberes docentes (pessoais e profissionais) possuem relevância, vez que são estudados como resultado da reflexão dos docentes sobre suas próprias práticas. Utilizamonos de abordagem qualitativa de pesquisa e, como método, o estudo de caso. Nessa perspectiva foram realizadas observações da prática docente, assim como entrevistas individuais com os professores, sujeitos do estudo. Os resultados da pesquisa permitem concluir que a busca por uma identidade para o curso em questão - locus da pesquisa - passa necessariamente pela construção coletiva da sua concepção pedagógica mediante a renovação contínua das práticas do seu corpo docente, seu processo de formação e autoformação continuada e, evidentemente, pela reflexão sobre o fazer didático-pedagógico no cotidiano da sala de aula.
\end{abstract}

PALAVRAS-CHAVE: Práticas educativas. Ensino de pós-graduação; Formação docente.

\section{Introdução - o contexto da pesquisa}

Na nova etapa de acumulação capitalista o conhecimento e a técnica ganham importância como insumo para a produção, ampliando as possibilidades de competitividade entre os países e organizações. A universidade, como locus privilegiado de produção do conhecimento e formação de recursos humanos vive o desafio de ampliar e diversificar a sua atuação na sociedade, no sentido de atender às urgências colocadas pela complexidade social. (SILVA JÚNIOR, 1996)

A formação e requalificação de profissionais para um mercado de trabalho reconfigurado e em constante transformação é um dos desafios a serem enfrentados por essa instituição. Se, até então, a atividade de ensino na universidade se expressa na
Cristina d'Ávila Maheu

Professora Adjunta da Faculdade de Educação/UFBA

cristina@didateca.org 
vinculação fundamental do trabalho do professor com a pesquisa e no caráter mais cultural do que profissional, as necessidades apresentadas pela nova conjuntura exigem que a universidade incorpore uma nova lógica, com a adoção de novos desenhos curriculares, inovações de natureza tecnológica, conhecimentos instrumentais em estreita vinculação com as necessidades imediatas do mercado de trabalho. (CHAMLIAN, 2003)

É nesse contexto que surgem no Brasil, na década de 1990, os Mestrados Profissionais. Liderada pela Coordenação de Aperfeiçoamento de Pessoal de Nível Superior (CAPES), no âmbito de um processo de reflexão sobre o modelo de pós-graduação brasileira, a regulamentação dos Mestrados Profissionais (MP), mediante a Portaria n. 080/98, traz como proposta a criação de cursos de natureza qualitativamente diferente dos mestrados acadêmicos. Os MP teriam como características: a articulação entre uma base de pesquisa consolidada; produção científica e técnica; corpo docente qualificado academicamente e com experiência gerencial; desenhos curriculares e estratégias inovadoras de ensino-aprendizagem, articulados às experiências profissionais dos alunos e às demandas socioeconômicas.

O Mestrado Profissional, investigado no quadro de uma Universidade pública na Bahia, vive no seu fazer cotidiano, os desafios: a) combinar a formação e requalificação profissional para um mercado extremamente volátil com o rigor e a qualidade acadêmica; e b) articular as experiências profissionais e as expectativas imediatas dos alunos com as práticas pedagógicas consolidadas dos docentes, até então, na sua maioria, dedicados à formação de professores e pesquisadores.

Não são desafios pequenos. Implicam na necessidade de elaboração de uma concepção pedagógica que, a partir da experiência de cada docente, seja o fio condutor que dê significado aos saberes e práticas compartilhadas com os alunos, inclusive redefinindo expectativas e demandas. Essa construção tem como ponto de partida o compromisso com uma universidade críticoreflexiva, a qualidade do ensino, o exercício da relação teoria prática e a conquista de níveis crescentes de interdisciplinaridade.

Partindo-se das premissas que: a) as práticas docentes expressam, de forma intencional ou implícita, saberes (conhecimentos, habilidades e atitudes) consubstanciadas em visões de mundo, de sociedade e de ciência; e, b) que as práticas docentes não se res- 
tringem apenas ao estritamente pedagógico, estando essencialmente vinculadas com as formas de organização e distribuição do conhecimento em uma determinada sociedade; c) que saberes profissionais são mobilizados e gerados no seio da prática profissional, este trabalho pretende analisar a experiência de construção cotidiana das práticas educativas de um curso de Mestrado, à luz da explicitação dos saberes docentes vinculados à natureza e intencionalidade de seus trabalhos.

As questões que orientaram esta pesquisa exploratória foram as seguintes: Como os professores percebem e analisam suas práticas pedagógicas no contexto do curso? Que saberes são mobilizados, produzidos e reconstruídos nesse processo de análise de suas práticas? Em que medida as práticas docentes, tomadas coletivamente, contribuem para a construção de uma identidade pedagógica para este curso de mestrado?

Para começar a entender o caminho trilhado e vislumbrar o muito a percorrer, foi realizada uma pesquisa de cunho qualitativo, um estudo de caso, com 53\% dos professores que atuam no referido curso. Os procedimentos de coleta de dados utilizados foram entrevista semi-estruturada e observação de aulas, com registro, por escrito. Foram realizadas observações de aulas ministradas por 38\% dos professores da amostra.

O interesse foi identificar qual a visão dos professores sobre a natureza do MP, como percebem o desenho curricular e o confronto teoria-prática no currículo e, no bojo dessas questões, reside uma outra especialmente importante: que saberes são mobilizados e reconstruídos nesse processo de análise de suas práticas? Finalmente, como essas visões compartilhadas podem contribuir para a construção da concepção pedagógica do curso.

Este MP nasce em 1998, logo após a regulamentação dessa modalidade de curso pela CAPES, integrado a um Programa de Pós-Graduação consolidado, oferecendo cursos de doutorado e mestrado acadêmico e um programa de cursos de especialização. O referido Programa conta com grupos de pesquisa, corpo docente qualificado, boa produção docente e discente, condições adequadas de infra-estrutura, além de boa imagem institucional.

Com relação ao perfil do corpo discente, verifica-se uma concentração de alunos do sexo masculino (em média, 70\% masculino e $30 \%$ feminino) e uma média de idade superior àquela observada no Mestrado Acadêmico (35 a 45 anos). A diversidade 
do corpo discente se expressa principalmente pelas áreas de formação profissional: embora se verifique historicamente a predominância de engenheiros (em média 50\%), com exceção da turma que ingressou em março 2004 onde os administradores representam 32\% da sala, as turmas (em média com 35 alunos) reúnem profissionais de diferentes formações nas áreas de exatas, humanas e de saúde: processamento de dados, comunicação social, psicologia, economia, ciências contábeis, secretariado, etc. Essa diversidade se estende à inserção profissional dos alunos: oriundos de diferentes segmentos da economia - secretarias estaduais e instituições públicas (10\%), empresas do setor privado (78\%) e organizações ligadas ao terceiro setor (12\%). Eles se situam em postos relativamente altos na hierarquia das organizações e a maioria (em média, 59\%) tem mais de 10 anos de experiência na profissão. A maioria ocupa cargo de média gerência (em média $70 \%)$, embora seja crescente, nas turmas mais recentes, a presença de profissionais não-gerentes, profissionais autônomos, recémaposentados, consultores, etc. Naturalmente que essa diversidade vem acompanhada por diferentes expectativas e experiências anteriores diversificadas que são, ao mesmo tempo, enriquecedoras e desafiantes para os professores e para os responsáveis pela gestão pedagógico-acadêmica do curso.

Quanto ao perfil dos professores, a grande maioria é doutor (90\%) e tem atividades fora da academia, seja como executivos em organizações públicas e privadas, seja como pesquisadores e consultores. A diversidade do corpo docente do MP, formado por 30 professores, se expressa pelas diferentes áreas de formação e doutoramento: finanças, estatística, psicologia, comunicação, educação, ciência política, CETT, administração pública, economia, direito, gestão estratégica, sociologia, etc. O Curso conta também com professores convidados tanto de outras unidades de ensino da universidade quanto de programas de pós-graduação do Brasil e exterior.

\section{Referencial Teórico: saberes e práticas docentes}

Concepções, saberes e representações não são conceitos antagônicos, pois são modalidades do pensamento humano, organizam e dão sentido ao mundo que nos rodeia. No contexto desta pesquisa, comprovamos a distância entre as práticas discursivas

92 R. Faced, Salvador, n.12, p.89-109, jul/dez. 2007 
e as crenças, vez que os docentes, sujeitos da pesquisa, sem formação pedagógica, se encontram, em grande parte, sem consciência explícita de suas escolhas didático-pedagógicas. Na medida em que o processo de pesquisa confrontou numa triangulação de dados provenientes de observação da prática docente, dados de entrevista e as avaliações dos alunos, buscou-se desvelar os saberes que sustentam as práticas docentes.

A noção de saber que assumimos aqui é inspirada nos estudos de Tardif (2002) e engloba, num sentido amplo, os conhecimentos, as competências, habilidades e atitudes ou o que convencionamos chamar de saber, saber fazer e saber ser. Ao que acresço a dimensão do saber sensível, vinculado à experiência estética e lúdica. Esses saberes, diferentemente das representações em estado inconsciente, refletem o que os profissionais dizem de seus próprios saberes profissionais. No caso deste estudo, interessa saber como os professores integram esses saberes a suas práticas, os produzem, transformam e os ressignificam no seio do seu trabalho. Portanto, compreender a natureza desses saberes, assim como o papel que desempenham no bojo do trabalho docente e na construção de sua identidade profissional, constituiu-se em tarefa primordial neste estudo.

Neste trabalho destacamos como referencial teórico, para explicitação da noção de saberes docentes, os estudos de Tardif (2002), Tardif e Lessard (2005), Cunha (1992) e Therrien (apud NUNES, 2001). Recorremos a D'Avila (2002b) para a discussão sobre interdisciplinaridade, e Libâneo (1990) para discorrer sobre as tendências pedagógicas e os estruturantes didáticos na prática docente (planejamento, métodos, avaliação da aprendizagem).

A compreensão de que concepções pedagógicas presidem a prática docente dos professores abre possibilidades de crítica e incentiva a construção de novos paradigmas para o ensino. A partir daí, pode-se entender o lugar especial que os professores assumem no processo ensino-aprendizagem. Embora a prática docente na universidade, como em qualquer outra instituição educativa, seja afetada por fatores independentes da vontade do professor, não há como desconhecer que, pelo grau de autonomia existente nesta instituição, o professor é o principal agente das decisões sobre a sua prática, inclusive influenciando a organização dos conteúdos e a forma como se distribui o conhecimento na sociedade. (CUNHA, 1998) 
A atividade docente é uma prática social complexa que combina conhecimentos, habilidades, atitudes, expectativas e visões de mundo condicionadas pelas diferentes histórias de vida dos professores. São, também, altamente influenciadas pela cultura das instituições onde se realizam. Na universidade esta atividade se situa no âmbito de uma instituição singular que se constitui por processos de diferenciação e convergências, relações formais e informais que se produzem no cotidiano. Nesse ambiente, os professores exercem a prática docente divididos entre os princípios da autonomia acadêmica, a lealdade à corporação, os princípios das suas disciplinas, os objetivos da instituição e às exigências da sociedade.

A prática docente é, portanto, um locus de formação e produção de saberes. Em seu confronto com a prática, e com as condições e exigências concretas da profissão, os professores estão continuamente produzindo saberes específicos, conhecimentos tácitos, pessoais e não sistematizados, que relacionados com outros tipos de conhecimento, passam a integrar a sua identidade de professor constituindo-se em elementos importantes nas práticas e decisões pedagógicas, inclusive renovando a sua concepção sobre ensinar e aprender. Esse tipo especial de conhecimento, construído a partir da prática docente, é o que Cunha (1992), entre outros, denominam de "sabedoria pedagógica" e Therrien (apud NUNES, 2001) chama de "saberes da experiência". Tardiff, Lessard e Lahaye (apud MONTEIRO, 2001, p.130) enfatizam que o saber docente é "um amálgama, mais ou menos coerente, de saberes oriundos da formação profissional, dos saberes das disciplinas, dos currículos e da experiência".

No estudo da epistemologia da prática profissional, interessa investigar sobre o conjunto de saberes utilizados pelos professores em sua prática profissional (é o que veremos adiante quando tratarmos dos achados da pesquisa). Não se pode confundir, por exemplo, saberes profissionais com saberes advindos dos estudos universitários. Estudos recentes demonstram, na atualidade, a que distância estão os professores entre o conteúdo de sua formação e sua prática pedagógica profissional (TARDIF, 2002). Por outro lado, há que se mencionar a força que exerce a prática na formação do profissional. Com efeito, o trabalho não é algo que se aprende conhecendo de fora para dentro, mas uma atividade que se cumpre e, como tal, no seio deste fazer, saberes são mobi-

94 R. Faced, Salvador, n.12, p.89-109, jul/dez. 2007 
lizados, construídos e reconstruídos. Foi isso que atestamos com essa pesquisa. Professores de pós-graduação, em nível de Mestrado profissionalizante, muitos profissionais de outras áreas, aprendendo a ensinar no chão da sala de aula entre ensaios e erros. Vale ressaltar aqueles que se mostram abertos à necessidade de formação pedagógica contínua.

De modo geral, podemos dizer, que mesmo estes profissionais que não passaram por cursos de formação, cursos de licenciatura, se fazem professores na ecologia de suas práticas. Formam-se na experiência e reflexões sobre si mesmo (autoformação), com os outros (co-formação) e no ambiente de trabalho, na própria organização (eco-formação). Nesta linha de pensamento haveremos de concordar que os professores não são, parafraseando Tardif (2002), "idiotas cognitivos", cuja atividade é determinada pelas estruturas sociais, pela cultura dominante, pelo inconsciente, etc. Esses professores, os pesquisados, nos deram provas definitivas de que sabem ensinar, de que são possuidores de uma competência profissional significativa. Os profissionaisprofessores (profissionais de outras áreas que passam a lecionar sem formação pedagógica), a nosso ver, são atores autores e portadores de saberes provindos da experiência, sobretudo.

Os saberes profissionais são, pois, saberes da ação. Essa hipótese reforça a idéia de que os saberes profissionais são trabalhados e ressignificados no contexto do próprio trabalho. Ou seja, é sobre as situações dilemáticas ou de conflitos que se remodelam os saberes com vistas às respostas impostas no cotidiano.

Podemos citar como características dos saberes profissionais dos professores, de acordo com Tardif (2002):

a) A temporalidade: que significa dizer da provisoriedade e construção histórica dos sabres; constituídos, assim, na trajetória ou itinerância de cada um. Essa itinerância inclui, evidentemente, as histórias de vida dos professores, suas experiências também como alunos que foram; além disso, diz respeito ao ciclo profissional.

b) A pluralidade dos saberes, no sentido de que eles provêm de diversas fontes - cultura pessoal, cultura escolar e formação acadêmica, além de outras. Podemos citar por exemplo, os autores que lemos e sobre os quais estudamos sobre o conhecimento didático-pedagógico. São saberes também heterogêneos vez que os professores não trabalham com 
uma única teoria pedagógica; eles as mesclam em função dos vários objetivos que possuam.

c) A personalização e contextualização dos saberes: São saberes que nascem em contextos sociopolíticos diferenciados, e provêm de pessoas humanas carregadas de marcas pessoais, culturais e subjetivas, o que define o perfil, a identidade de cada um na sala de aula.

d) O trabalho com seres humanos - requer conhecimento dos alunos de si mesmo e das interações que se fazem no jogo da sala de aula, o que marca definitivamente o trabatho do professor com base em estudos da psicologia e da psicopedagogia.

Por último, devemos dizer que, na universidade, nossas práticas são pouco investigadas. Em cursos como o mestrado profissional que investigamos, por exemplo, a situação é ainda mais complexa, pois paira a impressão sobre os docentes de que eles não são verdadeiramente profissionais do ensino. E que, por isso, tais práticas não são objetos legítimos de pesquisa e de trabalho pedagógico mais profundo, no sentido da formação permanente. A atenção aos aspectos pedagógicos na prática docente, em cursos de bacharelado ou nos mestrados acadêmicos ou profissionalizantes de outras áreas que não a área de educação, é extremamente limitada. Desta forma, questiona-se, problematiza-se pouco o fazer desses profissionais, levando-os a deitar um véu sobre os saberes que são capazes de produzir, mobilizar ou ressignificar. Foi nesse sentido que voltamos nosso olhar para a prática docente desenvolvida especificamente no contexto de um curso de pós-graduação de uma universidade pública. Que representações possuem de sua prática profissional? Que saberes advêm de suas práticas profissionais? Como os mobilizam e ressignificam, gerando novas aprendizagens?

Nesse sentido, sustentamos que as práticas docentes dão vida ao currículo e materializam as concepções pedagógicas, extrapolando as práticas docentes individuais e se expressando em aspectos como: a estrutura curricular, a articulação entre as áreas de conhecimento, disciplinas e atividades, a articulação entre as disciplinas e seus objetivos, as metodologias de ensino, as práticas de avaliação de aprendizagem, forjando a identidade da experiência educativa. 
Daí a importância de criar oportunidades para que os professores falem e reflitam sobre as suas práticas, compartilhando os desafios vividos, as alternativas de superação adotadas, na perspectiva de construir e consolidar uma identidade pedagógica integradora para a atividade educativa. Nessa medida, tornar-seão capazes de, como educadores, ganhar consciência dos saberes pedagógicos construídos no bojo de suas práticas profissionais.

Quadro analítico da pesquisa

Tomando-se como premissa básica que as práticas docentes se apóiam em saberes profissionais constituídos na itinerância de cada docente e que os professores, mediante as suas práticas, dão vida às propostas curriculares, adotou-se as seguintes categorias e indicadores analíticos:

a) Saberes profissionais: fundamentos psicopedagógicos, didáticos e filosóficos oriundos e orientadores da prática docente, explicitados nas práticas de:

- Planejamento Integrado (planejamento do ensino; fundamentos de interdisciplinaridade aliados ao planejamento);

- Metodologia de ensino (métodos, técnicas, instrumentos e recursos didáticos utilizados no trabalho docente);

- Avaliação da aprendizagem: representações e práticas da avaliação da aprendizagem, seus fundamentos e principais instrumentos.

b) Natureza e especificidades do curso de MP: concepção pedagógica e estrutura curricular do curso.

Para a finalidade que pretendemos, vamos nos ater, neste trabalho, aos aspectos relativos às representações e saberes docentes sobre suas práticas educativas.

Alguns Resultados

Tomando-se por base os dados levantados nos depoimentos dos professores e nas observações das aulas, confrontados com as categorias de análise, anteriormente descritas, é possível apresentar os resultados que se seguem.

No que tange à categoria Saberes profissionais (psicopedagógicos, didáticos e filosóficos oriundos e orientadores da prática docente), é importante mencionar, de início, que nos 
relatos das suas práticas docentes - a forma como dão aula, como organizam os conteúdos, os métodos e estratégias de ensino que utilizam, como fazem a avaliação, etc. -, nenhum dos professores entrevistados vincula suas experiências a qualquer concepção pedagógica de forma explícita. Mas ao relatar suas práticas e justificar suas escolhas, permitem que se façam algumas considerações a respeito, as quais serão apresentadas a seguir. Tomaram-se como elementos para esta análise as entrevistas e as observações das aulas, procurando-se identificar nas práticas docentes uma filiação com as teorias pedagógicas, não de forma exclusiva, mas como tendências.

Convém mencionar que, historicamente, no campo da educação e, mais especificamente do ensino, foram se constituindo, a partir da reflexão teórica sobre o ensinar e aprender, diferentes concepções que procuram explicar e dar sustentação filosófica e conceitual às práticas de ensino desenvolvidas no âmbito da instituição escolar. Essas concepções, ou tendências pedagógicas, estão intimamente relacionadas com a dinâmica social, sendo elas próprias fruto das concepções de mundo, homem e sociedade, predominantes em cada momento histórico.

No Brasil, a partir da segunda metade do século XX, três tendências assumem fundamental importância, pela influência que exercem na produção teórica sobre a educação e o ensino e nas práticas docentes desenvolvidas nos diferentes níveis de ensino e tipos de instituições educativas. São elas: a pedagogia crítico-social dos conteúdos, a pedagogia de Paulo Freire e o construtivismo.

Observou-se, no presente estudo, que a pedagogia crítico-social dos conteúdos (LIBÂNEO, 1986) ou histórico-crítica (SAVIANI, 1991) parece ter sido a tendência preferencial na prática educativa da maioria dos professores entrevistados - como se poderia supor, uma vez que tal tendência pedagógica é significativamente voltada para o ensino de adultos em geral. Essa pedagogia tem como características centrais: o acento nos conteúdos e desenvolvimento do pensamento crítico. São o professor e os alunos, sujeitos do ato educativo. O objetivo maior dessa pedagogia está na transmissão/assimilação do saber universal socialmente produzido. Do ponto de vista didático-pedagógico, o ponto nevrálgico reside no trabalho dos conteúdos das disciplinas, a partir da experiência social concreta dos educandos, mediado pelo professor.

98 R. Faced, Salvador, n.12, p.89-109, jul/dez. 2007 
A pedagogia crítico-social dos conteúdos tem como características centrais a ênfase na transmissão/assimilação do saber socialmente produzido, de forma crítica, com a mediação do professor. As práticas de ensino, segundo essa perspectiva, devem possibilitar:

a) identificação das formas mais desenvolvidas em que se expressa o saber objetivo produzido historicamente, reconhecendo as condições de sua produção e compreendendo as condições de sua produção e compreendendo suas principais manifestações bem como as tendências atuais de transformação;

b) conversão do saber objetivo em saber escolar de modo a torná-lo assimilável pelos alunos no espaço e tempo escolares;

c) provimento dos meios necessários para que os alunos não apenas assimilem o saber objetivo enquanto resultado, mas apreendam o processo de sua produção bem como as tendências de sua transformação. (SAVIANI, 1991, p.17)

Verificamos, ainda, na maioria dos professores entrevistados, uma predileção pelo trabalho com análise e interpretação de conteúdos críticos e uma preocupação voltada para questões de natureza sociohistórica na formação do alunado (subcategoria Metodologia de Ensino). Pode-se evidenciar, por exemplo, em entrevista realizada com um dos professores, sua preocupação com o "ensinar a pensar". Na observação da sua aula pode-se constatar que este, com tranqüilidade e segurança, orientava a discussão a partir da leitura e análise de textos. Salientava o conteúdo da disciplina, chamando a atenção dos alunos para o desenvolvimento do espírito crítico: "Nesse campo não há verdades estabelecidas... cada palavra está permeada de significados... de ideologia. Esse texto nos chama a atenção à propriedade do uso de conceitos em Administração".

O professor observado retomava conceitos, explicitava e estimulava o debate. Sua pedagogia, nesse contexto, parecia bem pautada nos princípios da tendência crítico-social dos conteúdos. Sua aula finaliza com a retomada e atualização de conceitos explorados no debate em sala.

Opção por métodos de ensino-aprendizagem inspirados na concepção construtivista pode-se observar na prática docente de poucos professores. Nesta tendência pedagógica, aprender signi- 
fica construir um significado próprio, pessoal para um objeto de conhecimento objetivamente existente, conforme Coll e colaboradores (1991). O depoimento de um dos professores entrevistados evidencia uma modalidade de metodologia construtiva e lúdica, claramente inspirada na tendência construtivista:

Convidei professores, para apresentar três perspectivas: gestor na perspectiva econômica, gestor na perspectiva social ética, e o gestor na perspectiva internacional, e teve um jazz, foi muito bonito, primeiro passei os textos e eles (alunos) se estruturaram para exatamente se identificarem enquanto gestor de uma banda de jazz, como gestor de uma organização contemporânea com a flexibilidade com a interação, com inspiração. O maestro foi exemplificando, falou em tocar garota de Ipanema para gringos, no Caribe, ele mostrou como adaptou. Os instrumentos representaram as competências, quantas variações ele experimenta, todas as variações que ele se permite.

A pedagogia construtivista toma como premissa básica que aprender significa construir um significado próprio, pessoal para um objeto de conhecimento objetivamente existente. Nessa perspectiva, o ensino não é um processo que conduz a acumulação de novos conhecimentos, mas que promove a integração, transformação, estabelecimento de relações e coordenação entre esquemas de conhecimentos preexistentes nos indivíduos, com diferentes graus de estrutura e relações que variam a cada aprendizagem que realizamos. (COLL et al., 2001)

Segundo essa concepção, o conhecimento, que faz parte da cultura, precisa ser ressignificado por professores e alunos, no âmbito escolar. Só assim, o processo de ensino-aprendizagem se realiza. A mediação didática deve incidir na capacidade construtiva dos alunos, desafiando-os e instigando-os a construir a sua própria aprendizagem.

De forma similar um outro professor entrevistado alia o ensino ao teatro e a outras linguagens artísticas, tendo em vista recuperar do próprio aluno o seu posicionamento pessoal. A mediação didática, nesta tendência, é, então, um processo compartilhado, no qual "o aluno pode mostrar-se progressivamente competente e autônomo na resolução de tarefas, na utilização de conceitos, na prática de determinadas atitudes e em numerosas questões" (COLL et al., p. 22). A mediação didática, então, incide 
na capacidade construtiva do educando (em que pesem outras dimensões aí presentes, sociais, afetivas, políticas e outras), desafiando-o, instigando-o. Uma ajuda, segundo D’Ávila (2002a), que vai do desafio à demonstração mais minuciosa, da demonstração de afeto à correção, ajustando-se sempre às necessidades dos educandos.

A perspectiva da pedagogia libertadora - uma tendência também construtiva de educação, só que com um cunho sociopolítico mais evidenciado -, observou-se nos depoimentos e na prática de poucos professores. Nessa tendência pedagógica o aluno é o sujeito do processo ensino-aprendizagem, com enfoque sobre o universo social, profissional do aluno, convertendo-se em temas geradores para efeito de reflexões, debates e produções coletivas. Pode-se perceber, através do depoimento de uma professora, os contornos dessa corrente pedagógica:

Em termos de concepção eu já participei muito do processo de reforma de currículo [...] já acompanhei muitos. E então gosto muito de ler Paulo Freire, de ler Rubem Alves, a questão da diferença entre o professor e o educador, a educação bancária e a educação crítica. [...] Mas, me preocupo com essa coisa de ouvir o aluno, tentar trabalhar a partir do que ele traz de referência sem um fundamento pedagógico maior. Eu vejo o professor como orientador que dá rumos para que o aluno aprenda. Animaos, leva-os a refletir. Sou partidária da idéia do aprender a aprender.

Um dos professores entrevistados chega a declarar que sua pedagogia está voltada para o universo adulto, com suas características pessoais, profissionais e sociopolíticas. Nada mais "freireano", portanto, vez que a preocupação maior deste educador estava em constituir uma pedagogia que buscasse desenvolver a consciência crítica do alunado, tomando como ponto de partida, sua experiência política mais cotidiana.

A concepção libertadora, sistematizada por Paulo Freire, a partir das reflexões sobre a sua prática com educação popular, apóia-se numa visão dialética do ato de ensinar e aprender. Segundo essa concepção, "[...] educador e educandos aprendem juntos numa relação dinâmica, na qual a prática orientada pela teoria, reorienta essa teoria, num processo de constante aperfeiçoamento [...]"(GADOTTI,1999, p.253). Nessa perspectiva, a educação visa a autonomia intelectual do cidadão para intervir e transformar a 
realidade. A realidade dos educandos e suas experiências concretas de vida e trabalho se convertem em temas geradores para efeito de reflexões e debates que produzem novos conceitos. O foco central das práticas de ensino inspiradas nessa concepção é o desenvolvimento da consciência crítica do estudante, tomando como ponto de partida as suas experiências cotidianas.

Assim, as metodologias de caráter lúdico ou político corroboram a concepção pedagógica construtivista, ampliando o número de professores que demonstram uma opção por uma prática pedagógica nesse sentido, onde os alunos são os construtores do seu conhecimento. Aliam-se aqui características da pedagogia libertadora de Paulo Freire com os princípios metodológicos do construtivismo, por entender-se ser também de natureza construtiva a metodologia daquela teoria pedagógica.

A Profa. Dália, por exemplo, faz uso de dinâmicas de grupo, buscando os conceitos que trazem os alunos. Simulações vinculadas à atualidade com fornecimento de modelo de análise - alunos como consultores (a teoria na prática). O objetivo é compreender a realidade onde se inserem, permitindo a mudança de enfoque:

Eu faço muito tempestade cerebral, pra levantar, em geral, antes de introduzir conceitos eu gosto de saber que conceito eles trazem. Hoje mesmo, a aula é assim. Primeiro eu trabalho com o que eles têm de conteúdo, o que eles pensam de políticas públicas porque nessa parte todos eles têm uma experiência [...]. São as duas dinâmicas que eu uso fundamentalmente aqui: [...] eu introduzo a aula, apresentando uma política contemporânea que seja mais ou menos conhecida de todos. Eu tô pensando agora em trabalhar com a política social de combate à fome.

Na observação de sua aula, constatamos a apresentação e discussão, item por item, do seu plano de ensino. Põe à prova. Um aluno sugere novo tema: "Fome Zero no governo Lula". Inicia sua aula com uma problematização: "O que são políticas públicas?" Sua aula transcorre a partir de sucessivas problematizações ("O que nos diz o saber que temos? o que aparece com mais freqüência"?), levando os alunos à ressignificação e reconstrução de conceitos. Explora vários recursos: quadro, flipshart, datashow... Usa da técnica do brainstorming. Aproveita respostas dos alunos numa aula bem planejada e bem conduzida. Tudo, a postura da professora e a condução da sua aula, nos leva a crer que se baseia 
em princípios da pedagogia libertadora de Freire e um pouco do socioconstrutivismo.

O Prof. Cravo revela práticas construtivistas e descreve suas aulas: a primeira parte conceitual mais prática. Segunda parte: exercícios em grupo. O que aprenderam nas disciplinas: conteúdos e práticas. São reunidos quatro grupos por afinidade e solicitada a descrição dos conteúdos, habilidade e atitudes desenvolvidas. Pede-se para escrever uma narrativa, que pode ser dramatizada e/ou vivenciada. O resultado é a sedimentação de conteúdos, conhecimentos, habilidades e atitudes. O perfil do grupo é assim obtido na hora: "A vantagem é o seguinte, você relacionar teatro, música com conteúdos específicos de gestão", afirma o professor entrevistado.

Também de caráter construtivista sociopolítico, os professores Violeta e Girassol demonstram na prática observada, uma aula toda pautada sobre temas geradores, analisados e discutidos horizontalmente no grupo. Questões que, por vezes, provêm dos alunos - o professor conduz e reorienta a discussão no círculo. O conteúdo teórico parte das experiências práticas trazidas pelos estudantes. A base da relação professor-aluno está no diálogo. Os alunos fecham a aula com a produção de um conceito, os professores retomam e fornecem o feedback ao grupo.

Os saberes e práticas docentes deslindados têm em comum o destaque para o papel do professor no processo de ensino aprendizagem, seja como mediador, como facilitador ou como mestre-aprendiz. A mediação didática, como um processo compartilhado no qual alunos e professores juntos re-elaboram criticamente os conteúdos, contribui para dar sentido aos conhecimentos e transformar a realidade.

Esses dados permitem inferir que a tendência conteudista nas práticas dos professores entrevistados é predominante neste curso de mestrado, levando-se a supor que a concepção pedagógica crítico-social dos conteúdos (LIBÂNEO, 1986), seja a preferida pelos professores. Com efeito, $44 \%$ dos entrevistados se situaram desta forma a partir da análise das entrevistas; se somarmos às metodologias observadas e também reveladas nas entrelinhas das entrevistas, temos $69 \%$ de práticas pautadas no estudo de texto ou em aulas expositivas, contra $31 \%$ que fazem uso de metáforas lúdicas e analíticas e de metodologias mais construtivas, por assim dizer. Nessas práticas, o aluno é o sujeito do processo ensino- 
aprendizagem, o professor um facilitador e as experiências vividas em sala de aula possibilidades de reconstrução de saberes. Que observemos a fala de dois professores sobre suas metodologias:

Eu posso até dizer o que está escrito aqui, ó. Objetivos, tem duas coisas: uma é compreender a gestão da informação, outra é compreender a tecnologia a partir de uma abordagem sócio-técnica que eu lhe falei e outra dados e impactos. Então, tem várias coisas em impacto nas organizações. E isso aí como é que trabalha o conceitual através de leituras de artigos, acaba tendo uma abordagem mais sistêmica. [...] E a parte prática é deles. Quer dizer, a minha experiência é bom mas, a parte prática eles que entram. É a experiência deles que conta. [...] Nesse sentido está-se trabalhando com conteúdos e objetivos específicos, exatamente pra ver se o conceito tá bem formulado e se eles acabam aplicando. (Professor Crisântemo).

O Prof. Gerânio não demonstra conhecer teorias pedagógicas, mas na explicitação de sua metodologia de ensino, afirma: "O desenvolvimento do pensamento crítico é importante, em parte; temos que também agregar o conhecimento instrumental".

É notória sua preocupação com os conteúdos, acentuandose o aspecto instrumental do curso. O mesmo professor, em outra questão, salientou a necessidade de se avaliar individualmente os alunos. O professor Jasmim ressalta na sua fala a necessidade de ouvir e respeitar o outro, reconhecendo seus valores, mas sem abrir mão da transmissão de conteúdos críticos, o que sinaliza uma clara tendência pela pedagogia dos conteúdos: "Faço aulas expositivas, com participação dos alunos... Não dá pra abrir mão dos conteúdos. Isso não."

Em síntese, a maioria dos professores baseia suas práticas mais sobre o ensino do que sobre a aprendizagem. Todavia, em vez de especialistas que conhecem bem um tema e sabem explicálo (ou que sabem passar o conhecimento, como me dizem tantos profissionais-professores), precisamos de professores-pedagogos, profissionais do ensino e da aprendizagem (ou da ensinagem como disse Selma Pimenta). Capazes de criar situações estimulantes de ensino-aprendizagem em vez de legar aos alunos a responsabilidade na tarefa de "assimilar" o saber. Do ponto de vista metodológico, os professores foram enfáticos na utilização do 
texto na sala de aula como mola propulsora nas aulas: "Da leitura à prática, debates e críticas sobre o texto. A disciplina X lida com ações do dia-a-dia; o curso visa elevar o nível da discussão para uma reflexão mais analítica sobre a Administração Pública". Afirmou a professora Angélica.

Ouvimos de outros professores, assim como observamos em suas práticas, o uso reiterativo de aulas expositivas sempre baseadas nos conceitos trazidos pelos autores dos textos trabalhados na sala. A Profa. Margarida, por exemplo, utiliza-se de aula expositiva com debate, além de seminários. Acha difícil o link teoria / prática uma vez que os alunos "não lêem..." Prof. Crisântemo explicita os objetivos da disciplina, reafirmando que trabalha o aspecto conceitual da disciplina, mediante leituras de artigos e discussões. Do ponto de vista da prática, faz uso da experiência dos alunos e exercícios com aplicações de conceitos (entregues um mês antes de acontecer o módulo). Suas aulas são interativas: discussão a partir dos textos e exercícios. O professor afirma:

[...] a aula de hoje é uma aula invertida. Eu dei um texto pra eles lerem, dei um exercício pra eles fazerem, vamos pegar isso aí direto, depois colocar os conceitos em cima, que dizer, vou perguntar os conceitos pra eles antes. Em outras situações muitas vezes tem aspectos expositivos ou uma discussão de um texto pra depois aplicar isso aí. Eu faço uso de transparências, acho que na minha vida, o número de transparência não encolheu não. Aumentou.

A subcategoria Planejamento Integrado (aliando planejamento de ensino ao princípio da interdisciplinaridade), explicita a prática de conceber e desenvolver as ações pedagógicas docentes no contexto do MPA. Por mais que os professores considerem pertinente e desejável o planejamento integrado e a cooperação entre os pares, o estudo revelou que tal prática ainda não se tornou uma realidade. Do total de respondentes, $21 \%$ assinalaram que "há planejamento integrado" e que "já vivenciaram a experiência de planejar em parceria", enquanto, 79\% afirmaram o contrário. Os docentes demonstraram, entretanto, forte interesse em desenvolver tais atividades, como uma necessidade de "integração entre os pares e as disciplinas; trocas; maior comunicação entre os professores". Isso nos leva a crer que a questão do trabalho interdisciplinar, mesmo no ensino de pós-graduação, 
continua sendo um grande desafio para a educação. Muito dificilmente os professores se disponibilizam para as trocas e o trabalho compartilhado. Há razões de fundo, históricas para isto, mas como o espaço que temos é diminuto para tais digressões tendo em vista o objeto do presente artigo, não será possível fazê-lo aqui. Vejamos as falas de dois docentes sobre a estrutura curricular do curso:

Profa. Gardênia: "O currículo foi pensado do Indivíduo ao Gestor. As disciplinas pensadas de modo interdisciplinar, mas a prática tem sido fragmentária (as disciplinas são vistas como propriedades do professor).

O desafio do curso: fazê-lo aplicado".

Como ninguém pode integrar ou integrar-se com aquilo que desconhece, esse aspecto evidencia a prática de ensino fragmentária alertada pelos professores entrevistados

No tocante à Avaliação da aprendizagem, pode-se constatar que a opção maciça dos professores é por uma avaliação de caráter formativo e processual. Nessa categoria, a quase totalidade dos professores entrevistados declarou optar pela avaliação formativa. Sobre o tipo de avaliação pontual e classificatória, apenas um professor entrevistado se posicionou de modo mais tradicional com relação à avaliação:

Eu acho o seguinte: toda vez que eu vejo uma prova, etc, eu primeiro leio pra ver qual é a média das respostas e depois é que eu seleciono e classifico, está certo? Então, por exemplo, o cso a avaliação do caso está na capacidade do sujeito ler as variáveis que intervieram no caso, está certo? Mas, a avaliação tem de ser assim. Eu leio todos os casos e depois classifico e aí eu vejo mais ou menos os melhores, os médios e os piores.

A análise desses dados permite evidenciar que a escolha por um tipo de avaliação formativa e processual, não pontual ou classificatória, se coaduna com a tendência pedagógica críticosocial adotada pela maioria dos professores entrevistados do MPA. Atualmente, é mister que se entenda a avaliação como uma prática de processo, coerente com princípios pedagógicos emancipatórios, onde o educando possa ser visto como partícipe, sujeito ativo no seu processo de formação e na construção das aprendizagens. 
Desde Donald Schön (apud ZABALZA, 2004), a idéia do professor como profissional reflexivo ganhou corpo e tornou-se postulado nos estudos sobre profissionalização docente. Evitando reducionismos, o que esse estudioso advoga é que a prática profissional planejada e refletida gera conhecimentos. Por isso refletir não significa retomar e repetir os mesmos conhecimentos e argumentos, mas sim "documentar a própria ação", avaliá-la e auto-avaliá-la, implementando processos de ajustes que se façam necessários. (ZABALZA, 2004). Esperamos com este estudo ter contribuído para com tais reflexões e avanços.

\section{Considerações Finais: saberes e práticas reconsteladas}

Este artigo teve por objetivo analisar os saberes docentes provindos das práticas educativas em vigor no seio de um curso de pós-graduação. Partindo-se da premissa teórica que as práticas docentes são presididas por saberes profissionais constituídos na experiência docente, e valorizando o professor como principal agente das decisões sobre as suas práticas, dando vida e significado às experiências educativas, este artigo utilizou uma grade analítica composta por quatro categorias, tendo se concentrado, neste artigo, naquelas que dizem respeito aos Saberes Docentes. Os resultados da pesquisa apontaram para:

a) uma visão pedagógica assentada em práticas conteudistas, numa vertente crítico-social de ensino/aprendizagem;

b) a falta de clareza e explicitação de uma concepção pedagógica curricular e de planejamento, que permita níveis, crescentes de interdisciplinaridade e oriente práticas pedagógicas integradas;

c) metodologias mais pautadas sobre o ensino, ligadas à análise e interpretação de conteúdos e o desenvolvimento do espírito crítico, em que pesem os esforços individuais para imprimir nuances construtivistas a essa prática;

d) a escolha dominante dos professores por uma avaliação de caráter formativo e processual.

Com base nos resultados, defende-se a necessidade de contínua formação do seu corpo docente e por uma formalização coletiva de concepção pedagógica para o curso de pós-graduação 
investigado. A clareza quanto à concepção pedagógica do curso, a renovação de posturas didáticas alinhadas a concepções pedagógicas conscientes é ingrediente indispensável ao exercício da práxis educativa.

\title{
Professors' knowledges: a glance at pedagogical practices in a graduate program
}

\begin{abstract}
This paper shows the results of a research done in the context of a Master Program in a Public university in Bahia, Brazil. Its objective was to analyze the pedagogical practice which was taking place on the base of the professors own perceptions. We began contextualizing in the social, political and economical Brazilian framework, then we tried to identify the professors' knowledges about the nature and particularities of the program curriculum and how it is articulated with objectives, teaching approach, integrated planning, and practices of evaluation of learning. This research was born from a practice of continuous formation which was called didactic ateliers, a space to exchanges dilemmas, doubts, questions and knowledges about teaching. Through this one year atelier, the author had the possibility to know better the pedagogical practice of the professors. We then used a study case qualitative approach base on observations of teaching practices as well as individual interviews with the program's professors. We conclude that the program search for an identity only could be realized with a collective construction of its pedagogical conception through a continuous renewal of the teaching practices, of the process of formation and continuous autoformation, and obviously, through a reflection upon the didactic pedagogical action in the daily life of the classroom.
\end{abstract}

KEYWORDS: Educational practices. Graduate teaching. Teachers' formation.

\section{Referências}

CHAMLIAN, H. C. Docência na universidade: professores inovadores na USP. Cadernos de Pesquisa, n.118, p. 41-64, mar. 2003.

COLL, C.et al. O construtivismo na sala de aula. São Paulo: Ática, 2001.

CUNHA, Maria Isabel. O bom professor e sua prática. Campinas: Papirus, 1992.

Araraquara : JM Editora, 1998.

D'ÁVILA, C. M. Decifra-me ou te devoro: o que pode o professor frente ao manual escolar? 2002. Tese (Doutorado) - Faculdade de Educação - Universidade Federal da Bahia, Salvador, 2002.

D'ÁVILA, C. M. Interdisciplinaridade e mediação pedagógica. Revista da FEBA, Salvador, Bahia, v.1, n.1, p. 1343-158, jan./dez.2002.

GADOTTI, M. História das idéias pedagógicas. São Paulo: Ática, 1999. 

cas, 2000 .

Perspectivas atuais da educação. Porto Alegre: Artes Médi-

LIBÂNEO, J. C. Democratização da escola pública: a pedagogia crítico-social dos conteúdos. São Paulo: Loyola, 1986.

Didática. São Paulo: Cortez, 1990.

MONTEIRO, A. M. F. da C. Professores: entre saberes e práticas. Educação e Sociedade, Campinas, v. 22, n.74, p.121-142, 2001.

NUNES, C. M. F. Saberes docentes e formação de professores: um breve panorama da pesquisa brasileira. Educação e Sociedade, Campinas, v. 22, n.74, p.27-58, 2001.

SAVIANI, D. Pedagogia histórico-crítica: primeiras aproximações. São Paulo: Cortez, 1991.

SILVA JÚNIOR, J. dos R. da. Tendências do ensino superior diante da atual reestruturação do processo produtivo no Brasil. In: CATANI, A. (Org). A universidade na América Latina: tendências e perspectivas. São Paulo: Cortez, 1996. p.11-33.

SOARES, S. R. A construção do sentido de cidadania numa perspectiva pluricultural na formação de professores. [Salvador: s.n.], 2004. p.107117. Apresentado no evento Atos do Colóquio: Pluriculturalismo e Formação do educador: um diálogo entre Québec e Bahia. Salvador, dez. 2004

TARDIF, M. Saberes docentes e formação profissional. 2. ed. Petrópolis: Vozes, 2002.

LESSARD, C. O trabalho docente. Petrópolis: Vozes, 2005.

WOOD JR., T.; PAULA, A. P. P. de. O fenômeno dos MPAs brasileiros: hibridismo, diversidade e tensões. Revista de Administração de Empresas, v. 44, n.1, p.116-129, jan./mar. 2004.

ZABALZA, M. O ensino universitário, seu cenário e seus protagonistas. Porto Alegre: Artmed, 2004. 